\title{
CULTURAL INTEROPERABILITY - PREREQUISITE FOR THE RESPONSE TO HYBRID THREATS
}

\author{
Lucian ISPAS*, Paul TUDORACHE** \\ *"Nicolae Bălcescu" Land Forces Academy, Sibiu, Romania, \\ **"Carol I" National Defence University, Bucharest, Romania \\ ispaslucian04@yahoo.com, tudorache@yahoo.com
}

\begin{abstract}
Nowadays, in addition to the already known challenges, the hybrid threats require new responses, which had a timely appearance (adapting the existing military capabilities, the establishment of new military structures, at division and brigade level, their training etc.) and which involve an unconditional cooperation between NATO Member States and between them and their partners. From the perspective of the military response, creating multinational military structures based on different national contingents raises a number of questions on how they succeed to act coherently, in a coordinated and integrated manner. In this respect, the role of interoperability in general, and of cultural interoperability at the level of NATO military structures, in particular, has significantly increased, becoming a necessity for the development of multinational military operations as a joint response to the hybrid threats.
\end{abstract}

Keywords: cultural diversity, cultural differences, interoperability behavioral, interoperability, cultural interoperability, multinational military structures, multinational military operations, hybrid threats.

\section{Introduction}

The ongoing transformation of the security environment in general, and the emerging hybrid threats, in particular, have led NATO (the North Atlantic Treaty Organization - NATO) to adopt a series of measures that facilitate the adaptation of the existing capabilities and the improvement of their mode of action. In this regard, the NATO summit in Wales, held between September 4-5, 2014, NATO member states agreed on the implementation of NATO's capability to respond effectively to the challenges posed by hybrid threats, where a broad spectrum of visible and covert military, paramilitary and civilian actions are engaged in a highly integrated design [1] by different actors (state, non-state, embryo state) at different levels (tactical, operational, strategic), in different regions (the ex-Soviet space, the area controlled by ISIS between Syria and Iraq, Iran, China etc.) [2]. The establishment, the training and the use of multinational military structures for conducting multinational exercises/operations or for other purposes, as part of the response to hybrid threats and not only, generates a series of challenges regarding the achievement of cultural interoperability, i.e. identifying an answer to the question How do national contingents within multinational military structures succeed to act jointly, timely, coherently, in a coordinated and integrated manner?

Even if the analysis of cultural diversity within multinational military structures is not novel, and has been addressed countless times both in national and international scientific conferences, as well as in 
specialized journals and magazines, trying to understand how cultural differences influence the activities and actions of the static (multinational headquarters) or action (multinational military operations) multinational military structures and solving the problems generated by them, are essential in achieving the cultural interoperability of multinational military structures.

\section{Cultural interoperability - a "must have" of the NATO multinational military structures}

From our point of view, interoperability in general, and cultural interoperability, in particular, are closely related to the concept of multinational military operations. Quite often, cultural interoperability has been identified as a prerequisite for multinational cooperation, with current estimates highlighting that, even more so in the future, NATO multinational forces will not be able to operate within multinational military operations without achieving an optimal level of cultural interoperability.

In addition to doctrinal interoperability, the cultural interoperability stands out as a component of behavior interoperability [3] defined as the dimension of interoperability that manifests as individual and group actions determined by their perceptions on the security environment [4]. Generally, cultural interoperability refers not only to the ability of a military to work together with other soldiers from different cultures, but also to the mutual understanding in a joint multinational environment [5]. On the other hand, we must be aware of the fact, that, in addition to providing contact, dialogue and interaction between the military, cultural interoperability also encompasses the influences that they can reciprocally transmit and receive [6].

Starting from the definition of the concept of interoperability formulated by NATO as "the ability of the Allies to work together coherently, effectively and efficiently, in order to achieve tactical, operational and strategic objectives" [7], we believe that a common denominator of the definitions given to cultural interoperability should be built on that ability by which the capabilities of various national military contingents interact positively, in order to solve the cultural diversity problems so as to achieve common tactical and operational objectives and accomplish the end state specific to the multinational military operation.

In a multinational military context, the conduct of a military or of a military structure is influenced by the characteristics of the environment in which it operates, but also by a number of factors specific to the politico-cultural, organizational, cultural and individual-cultural fields [8]. In this respect, cultural interoperability can be described both by institutional prescriptions and guidelines and by the national constitution, the legal system, and their national customs and own culture. Specific to the politico-cultural field, the national laws and the constitution limit the manner in which a military force/national military contingent can be used, i.e. in what regards the missions which they can participate in. Some national contingents are subject to legal limitations regarding their involvement in different types of missions outside the national territory, and for others, there are limitations regarding the engagement to carry out missions under the command of a certain nation. [9] On the other hand, the rules of engagement (RoE) can influence military actions during multinational military operations. The national rules of engagement may differ from one nation to another. Using a common denominator for the RoE (transnational RoE) can be an appropriate solution to meet the demands of the security environment, but the differences of interpretation at national level should not be ignored. [10] For example, national contingents can have different perceptions of the concepts of hostile intention, hostile action, self-defense etc. 
At the organizational-cultural level, the own national repertoire also influences the use of force/risk-taking during multinational military actions. In Afghanistan, for example, the Romanian military contingents needed more time to conduct specific analyses, to check other sources before launching a division to confirm or deny the threat represented by improvised explosive devices (IEDs). Unlike the Romanian military structures, the US military appropriately engaged subunits in order to reduce the likelihood that the IEDs be initiated by other subunits, based on short, qualitative analyses. [11].

Lastly, at the individual-cultural level, achieving cultural interoperability in order to understand the situation and to boost the efficiency of the joint military action, involving all the members of the multinational structure can be achieved based on knowledge and mutual trust [12], where the greatest influence is given by the cultural / intercultural training of the military and by the use of a common operational military language.

In what regards the intercultural training of soldiers, it can happen both in a local and in a new environment. The training of the deployable military structures should not be done randomly, but must be integrated into all pre-deployment training activities, conducted in relation to the position that each military will occupy in the multinational military structure. Cultural/intercultural training is addressed to all members of the deployable military structure, regardless of the rank, position, gender etc. Perhaps more emphasis should be placed on those soldiers who will occupy key positions of responsibility and on those who will serve in multinational headquarters. The resources that can be employed include:

- Specialized textbooks and journals, cultural/intercultural guides, handbooks and cards [13] to provide information and examples of relations that can be used as reference during the cultural/intercultural activities

- Roles-plays during the multinational military exercises [14] including Blue Forces (BLUFOR), Opposing Forces (OPFOR), civilians on the battlefield (COB), interpreters (TERP); such predeployment training exercises of various military structures take place in the Combat Training Centre for Land Forces "Getica"CIL-FT;

- Distributed training exercises using distributed simulation, where the participants operate real, virtual and constructive systems, using different platforms connected to a network (with at least one node), in different locations, based on a common scenario; the system of virtual simulation Virtual Battlespace 3 VBS3 used at CIL-FT in version 2 for small groups training before the mission (up to company level) is extremely resourceful, as it facilitates the checking of knowledge regarding operating procedures, and, perhaps most importantly, most often during joint exercises with forces belonging to other nations (e.g. a detachment of Romanian-American-British special forces executing a kinetic mission into the enemy environment).

The second variable of cultural interoperability at an individual-cultural level is the operational military language, defined as the common language (English, French), and the use of acronyms, symbolism, and different manners of formulating the mission and setting tasks based on mission/task verbs etc. Since the majority of the NATO member states have made considerable efforts to learn English, the problem is somehow resolved; in terms of knowing the acronyms, symbols and in what regards the formulation of the missions and establishing the tasks, there are some differences (mostly in terms of interpretation), which arise especially during moderate and high intensity multinational military actions. Military research has shown that joint operational 
military language can be improved, especially by conducting joint multinational exercises and by common participation in all the phases of the planning process of multinational operations.

These are just a few aspects to be considered in order to achieve an optimal level of cultural interoperability, as required by multinational military structures, without which NATO cannot plan the deployment and conduct of multinational military operations in the present and especially in the future. From our point of view, NATO should undertake more efforts so as to build up the capacity to anticipate various threats, in order to develop doctrines and strategies for resolving them. NATO is facing some problems in determining a common doctrine on achieving the cultural interoperability of its military structures [15], although one should have already been implemented until now. Only in this way will NATO have the opportunity to design and submit consistent, efficient and effective responses to hybrid threats.

\section{Conclusions}

The annexation of Crimea by the Russian Federation is just one example of using strategies specific to the hybrid war, a threat which currently has a growing trend of expansion. If today's hybrid threats are on the agenda of most actors, generators of security, in the future we may witness a transformation towards a higher level, as we have witnessed a smooth transition from conventional threats to unconventional/asymmetric and finally to hybrid threats. Faced with these challenges entailing a permanent transformation of the security environment, NATO's obligation to think, generate and apply appropriate answers that in the best cases lead to a partial solution is not sufficient.

Based on the old saying that "prevention is better than cure", NATO should certainly channel more efforts towards developing the ability to anticipate new security risks and improve joint action to combat them. Without cooperation between partners, without the joint efforts of all NATO members and beyond, we can not give quality responses to the requirements of the security environment. In this way, the development and improvement of cultural interoperability as an element of behavioral interoperability at NATO level is among the main priorities of the alliance in its attempt to move from a cause-effect resolution to a prospective one, which is based on anticipating risks and taking measures to amend the initial conditions of manifestation.

\section{References}

[1] Enrico Fassi, Sonia Lucarelli, Alessandro Marrone, What NATO for what threats, Warsaw and Beyond, NATO HQ - Boulevard Léopold III, 1110 Brussels - Belgium, 2015, p. 9.

[2] Ibidem, p. 10.

[3] Michael Codner, Hanging together: Interoperability within the alliance and with coalition partners in an era of technological innovation, Royal United Services Institute for Defence Studies Whitehall, London, United Kingdom, Final Report, June 1999, p. 13.

[4] Ibidem, p. 23.

[5] Colonel Philippe Berne, Addresing the issues of interoperability, in Doctrine - general military review, Interoperability the challenge, No 11, April 2007, p. 11.

[6] Paul Tudorache, Mircea Cosma, Dimensiunea interculturală a formării ofiterului din Forțele Terestre, "Lucian Blaga" University Publishing House, Sibiu, 2015, p. 60.

[7] http://www.nato.int/cps/en/natolive/topics 84112.htm, retrieved on February 21, 2017.

[8] Paul Tudorache, Mircea Cosma, op.cit., p. 75.

[9] Michael Codner, op.cit., p. 23.

[10] Ibidem, p. 23. 
[11] Paul Tudorache, Mircea Cosma, op.cit., pp. 77-78.

[12] Colonel Yves Beraud, Towards a draft of an interoperability policy for the French Army, în Doctrine - general military review, Interoperability the challenge, No 11, April 2007, p. 35.

[13] Paul Tudorache, Mircea Cosma, op.cit., p. 98.

[14] Ibidem.

[15] Thomas A. Crowson, Partnering and Army Doctrine: Indicators of Military Cultural Interoperability, available

on http://www.queensu.ca/cidp/sites/webpublish.queensu.ca.cidpwww/files/files/publication s/Policy\%20Briefs/CIDP_PolicyBrief_Spring2015.pdf, retrieved on February 21, 2017. 